Geopolítica(s) Revista de estudios sobre espacio y poder ISSN: 2172-3958

\title{
Cooperación para el desarrollo, gobernanza y nuevos escenarios internacionales
}

Carlo Tassara (2016) Cooperación internacional para el desarrollo: gobierno, economía y sociedad. Evolución de las políticas y escenarios futuros. Bogotá: Ediciones Unisalle. 132 pp. ISBN 978-958-5400-04-7.

En su último libro ${ }^{1}$, Carlo Tassara ${ }^{2}$ hace un recorrido completo de la cooperación internacional para el desarrollo (CID), analiza su evolución histórica y los marcos teóricos que la han caracterizado a lo largo de su proceso de transformación. Con esta obra el autor ofrece una excelente base para una sistematización exhaustiva de la materia, conduciendo al lector desde una perspectiva crítica que permite evidenciar tanto los éxitos como los fracasos y las contradicciones de la cooperación.

Tras un análisis atento del tema - en el que aborda los puntos de vista económico, social y político - su planteamiento ofrece además un bosquejo de los posibles escenarios futuros, más como punto de arranque que como punto de llegada, logrando abrir una vez más el debate, político y académico, sobre la cooperación internacional y su desarrollo.

Cabe destacar como el autor, con su estilo sencillo y claro, junto a las numerosas tablas y figuras empleadas, permite una fácil comprensión de la obra también a lectores poco familiarizados con estas temáticas. Del mismo modo, anima a sumergirse con brújula dentro del complejo mundo de la CID y de sus distintos tipos de ayudas. Para terminar, la última parte de la obra enfoca su reflexión sobre los posibles escenarios futuros, lo que sin duda configura una lectura útil no solo para estudiantes de posgrados, sino también para expertos, académicos y profesionales.

El prólogo de José Antonio Ocampo ofrece una primera clave de lectura del libro, haciendo referencia a la paradoja de la soberanía: "ningún país puede abordar por sí solo [sus] problemas [...], pero ninguno confía lo suficiente en los otros como para aceptar una coordinación efectiva que limitaría $[\ldots]$ su soberanía

Más información está disponible en URLs: <http://ebooks.lasalle.edu.co/product/cooperacin-internacionalpara-el-desarrollo>

$<$ https://www.academia.edu/30742176/Cooperaci\%C3\%B3n_internacional_para_el_desarrollo_gobierno_eco nom $\% \mathrm{C} 3 \% \mathrm{ADa}$ y_sociedad._Evoluci $\% \mathrm{C} 3 \% \mathrm{~B} 3 \mathrm{n} \_$de_las_pol\% $\%$ C3\%ADticas_y_escenarios_futuros $>$.

2 Es profesor en la Universidad de Roma La Sapienza y dicta clase de posgrado en diferentes ateneos colombianos. Más información está disponible en URL: $<$ https://uniroma1.academia.edu/CarloTassara $>$. 
convencional" (p. 7). Por el contrario, uno de los pilares de la nueva cooperación internacional es justamente la realización de un esfuerzo común para abordar de manera coordinada problemas que aquejan a varios países y a la humanidad en su conjunto.

En primera instancia, la obra de Tassara, inspirándose a autores como Lewis, Sen, Alonso, Sachs y Sanahuja, examina la evolución conceptual y teórica tanto del desarrollo como de la cooperación internacional. Retoma la definición de la Organización de las Naciones Unidas (ONU) del 1986 sobre el derecho al desarrollo y desde allí explica cómo alrededor de la cooperación se ha dado un proceso que ha contribuido a la valorización de la dignidad humana, dejando de ser puro asistencialismo y liberándose progresivamente de la óptica cínica e instrumental adoptada a partir de la Segunda Posguerra, cuando la CID representaba esencialmente un recurso a favor del posicionamiento político y geoestratégico de los dos bloques que protagonizaron la Guerra Fría.

Por otra parte, el libro contempla un análisis de los distintos períodos históricos desde la Segunda Posguerra hasta nuestros días y evidencia cómo se ha caracterizado la CID en cada uno de ellos, con sus paradigmas, sus sistemas de gobernanza y sus distintos actores. A lo largo de este camino, se entiende la importancia de la progresiva superación de la visión rostowiana del desarrollo y marshalliana de la cooperación internacional. Entre otras cosas, este cambio viabilizó el protagonismo de las organizaciones de la sociedad civil (OSC) y de los actores locales, que llevaron la cooperación al desarrollo hacia nuevas formas de interpretación y actuación. De la misma manera, el peso creciente de nuevos enfoques, como la cooperación Sur-Sur y la descentralizada, amplía el abanico de los actores involucrados y de las posibles soluciones, dejando atrás la clásica relación jerárquica entre donantes y receptores:

En este marco, la cooperación internacional —o por lo menos una parte de ellase parece cada vez más a un multiplicador de los procesos endógenos de desarrollo económico y social, donde del mismo modo, se orienta a dar apoyo a las experiencias más avanzadas que ya se están realizando en los distintos países, lo cual valoriza al mismo tiempo los recursos humanos locales (p. 88).

Lo anterior acompaña al lector en la reflexión sobre las transformaciones que han llevado al planteamiento de la actual agenda internacional, desde la configuración de los Objetivos de Desarrollo del Milenio (ODM) en 2000 hasta la disposición de los Objetivos de Desarrollo Sostenible (ODS) en 2015, que la Asamblea General de Naciones Unidas aprobó en el marco de un contexto calificado por el posicionamiento más asertivo de los países emergentes y el replanteamiento de las relaciones entre el Norte y el Sur del planeta.

Por lo que es pertinente el estudio detenido de los cambios que caracterizaron el 2015 y cómo eso ha afectado a la agenda post-2015. Por ejemplo, el autor da cuenta del envejecimiento de la población y la crisis económica que afecta los países industrializados, de la crisis de hegemonía de los Estados Unidos, del peso ascendiente de los países emergentes en general y de los BRICS ${ }^{3}$ en particular y del au- 
mento de los países de renta media. Aborda la caída de la hegemonía estadunidense, no solo a nivel económico sino también político e ideológico, que refleja fuertemente la evolución que está teniendo la CID y sus paradigmas. Eso porqué el área del Atlántico Norte está perdiendo su centralidad frente a la región AsiaPacífico: como plantea Zakaria ${ }^{4}$, estamos asistiendo a la creación de una era "postestadunidense".

En este nuevo escenario, los ODS aplican a todos los países del mundo y tienen el propósito de orientar tanto sus políticas nacionales como los esfuerzos conjuntos de la comunidad internacional para enfrentar temas centrales de gobernanza mundial en aspectos institucionales, económicos y ambientales. Por ende, la Agenda 2030 para el Desarrollo Sostenible, a pesar de algunas inconsistencias y limitaciones ${ }^{5}$, abre espacios novedosos para avanzar hacia una armonización internacional de algunas políticas públicas de relevancia estratégica. Dicho de otra manera, hay que "ir más allá de la discusión sobre la eficacia de la Ayuda Oficial al Desarrollo (AOD) y enfatizar la necesidad de mantener una coherencia entre todas las políticas públicas para promover el desarrollo" (p. 106).

Igualmente, el texto enumera tres posibles escenarios futuros de la CID:

a) minimalista: los ODS son interpretados reductivamente como la versión actualizada de los ODM dando prioridad a los países de renta baja de África y Asia;

b) securitizado: el énfasis se pone en temas como la lucha contra el terrorismo y la delincuencia internacional y el control de los flujos migratorios;

c) holístico: se impulsa una asociación global para el "desarrollo eficaz", valorizando los contenidos de la Declaración de Busan (2011) y "promoviendo un enfoque más sistémico [...] orientado a la solución en el largo plazo de los grandes problemas de la humanidad" (p. 110-111).

El autor no disimula su preferencia por el tercer escenario, pero reconoce que lo más probable será la afirmación de una mezcla de los tres, con la prevalencia de uno u otro según los equilibrios geopolíticos que se impongan a lo largo del tiempo. Se manifiesta además que los primeros dos escenarios dejarían rezagadas las prioridades de desarrollo de América Latina y el Caribe.

A pesar del interesante análisis propuesto, tal vez la tipología planteada en esta parte del libro no es explorada de forma cabal. Primero, porque no se reconoce lo suficiente la relevancia de los intereses políticos y económicos de un país como China, cuyo peso específico ha sido marginal en la negociación de la Agenda 2030, pero es central en los actuales equilibrios internacionales. Segundo, porque las potencialidades del escenario holístico parecen sobrevaloradas en un contexto mundial caracterizado por la mayor influencia de múltiples formas de nacionalismos y neosoberanismos. Lástima de qué a la fecha de la publicación del texto no permitió tener debidamente en cuenta las implicaciones de la Presidencia Trump sobre los escenarios formulados.

F. Zakaria: The post American World. New York: W.W. Norton \& Company, 2008.

Como la ausencia de referencias explícitas a la gobernanza del comercio mundial, la deuda pública, las inversiones extranjeras directas y los procesos migratorios. 
Sin embargo, queriendo esbozar una interpretación geopolítica de todo esto, se puede afirmar que el enfoque minimalista se acerca más a la postura de la Unión Europea (UE), que en su Programa para el Cambio ${ }^{6}$ (2011) propende por la rápida graduación del acceso a los fondos de AOD de los países de renta media alta; el enfoque securitizado es más coherente con la visión expresada por los Estados Unidos, y especialmente por su actual Presidente; mientras que el enfoque holístico se aproxima más a la posición de la Comunidad de Estados Latinoamericanos y del Caribe (CELAC), que puso al centro de su agenda post 2015 para el desarrollo la promoción de un "cambio estructural para la igualdad", con el propósito de eliminar las brechas existentes en la calidad de vida de la población más pobre y vulnerable a nivel internacional, regional y nacional.

Más allá de las diferencias antes mencionadas, otro valioso aporte del libro es una revisión crítica de las relaciones y la cooperación euro-latinoamericanas, que - sobre todo a partir de los años noventa ${ }^{7}$ - se plantearon como eje central de una hipótesis de asociación estratégica entre dos regiones que pertenecían una al Norte y una al Sur del planeta. Ahora bien, sin por un lado esta hipótesis no logró concretarse de manera efectiva, la CID realizada por la UE en la región representa un caso exitoso de cooperación entre pares, orientada a fortalecer la integración regional, la creación de capacidades y el diseño e implementación de políticas sociales, basada metodológicamente en el trabajo en redes y en el aprendizaje mutuo entre los actores involucrados.

Come se mencionó, otro tema relevante abordado por Tassara es el rol de la sociedad civil al interior de la CID en general y de los procesos de desarrollo humano sostenible en particular, sobre todo en los países emergentes, quienes son actores fundamentales para logar un futuro más digno para todos.

En resumen, este libro es una valiosa contribución al debate, académico y político, sobre la cooperación internacional. Su laborioso análisis permite aprovechar los contenidos de la publicación para reflexionar e interpretar la historia pasada y por esa vía mirar hacia el futuro de la cooperación para el desarrollo como una herramienta para mejorar el mundo en el que vivimos.

Marco Pellizzon

Magister en Cooperación al Desarrollo en la U. de Roma La Sapienza (Italia) Magister en Rel. Internacionales en la U. del Norte de Barranquilla (Colombia) Programa de doble titulación La Sapienza - Uninorte Email: marco.pellizzon89@gmail.com

6 Este documento establece la política de CID de la UE para los próximos años y plantea concentrar la cooperación europea en un número reducido de países, privilegiando los de renta baja, y prioridades (democracia, derechos humanos y crecimiento integrador).

7 Sin embargo, sus raíces remontan a principio de los años ochenta cuando la cooperación europea se consolidó como principal fuente de AOD tanto a nivel mundial como en la región. 